\title{
Halloysite Nanotubes as an Effective and Recyclable Adsorbent for Removal of Low-Concentration Antibiotics Ciprofloxacin
}

\author{
Rongqing Cheng ${ }^{1}$, Haipeng $\mathrm{Li}^{1}$, Zhiliang Liu ${ }^{1}$ and Chunfang Du ${ }^{1,2, *}$ \\ 1 College of Chemistry and Chemical Engineering, Inner Mongolia University, Hohhot, \\ Inner Mongolia 010021, China; xiaoxiaoqiu1203@163.com (R.C.); lihaipeng66666@126.com (H.L.); \\ cezlliu@imu.edu.cn (Z.L.) \\ 2 Hunan Key Laboratory of Mineral Materials and Application, Central South University, \\ Changsha 410083, China \\ * Correspondence: cedchf@imu.edu.cn; Fax/Tel.: +86-471-4994375
}

Received: 7 August 2018; Accepted: 31 August 2018; Published: 5 September 2018

\begin{abstract}
In this work, halloysite nanotubes (HNTs) without modification were used as an efficient adsorbent to explore its natural adsorption capability, which showed excellent adsorption ability for low-concentration ciprofloxacin (CIP). The physicochemical properties of HNTs before and after adsorption were investigated by several characterization techniques, including scanning electron microscopy (SEM), transmission electron microscopy (TEM), Fourier transform infrared spectroscopy (FT-IR), $\mathrm{N}_{2}$ adsorption-desorption analysis, $\mathrm{X}$-ray diffractometer (XRD), and zeta potential analysis. The influences of temperature, initial CIP concentration, adsorbent dosage, and $\mathrm{pH}$ value on CIP adsorption performance were also studied. The kinetics analysis revealed that CIP adsorption on HNTs was a kind of monolayer adsorption process and followed a pseudo-second-order rate equation. The zeta potential result indicated that electrostatic interaction between HNTs and CIP molecules was possibly responsible for the adsorption performance. Moreover, HNTs showed no apparent loss in CIP adsorption capability after five cycles, exhibiting potential applications in wastewater treatment.
\end{abstract}

Keywords: halloysite nanotubes (HNTs); adsorption; antibiotics; ciprofloxacin; natural adsorption capability

\section{Introduction}

Antibiotics have already become one of the important therapeutic medicines for human or animal diseases [1]; meanwhile, most antibiotics cannot be completely biodegraded in human or animal bodies and the residuals are excreted into the environment [2]. Among these antibiotics, ciprofloxacin (CIP) has attracted quite a lot of attentions and is one of the most important contaminants in the environment [3,4].

As is known that the residual CIP in water is toxic [5], which can result in antibiotic-resistant bacteria, a potential threat to human health [6,7]. It is thus of great necessity to dislodge ciprofloxacin from an aquatic environment. A large number of studies concerning chemical, physical, or biological treatments have been adopted to remove antibiotics [8]. In comparison, the chemical and biological methods have some drawbacks, such as a complex design process, low removal rate, high energy consumption, and so on [9]. Physical methods include ion exchange, solvent extraction, reverse osmosis, and adsorption [10-13]. Ion exchange, solvent extraction, and electrolytic processes are costly and sophisticated. Reverse osmosis is very effective, but the membranes are easily spoiled, which requires frequent replacement [11]. Adsorption is generally recognized as an effective way to remove pollutants due to its low cost, easy operation, and high efficiency. Active carbon with 
excellent adsorption characteristics is widely used as an adsorbent. However, its high cost restricts its commercial application. In contrast to active carbon, clays are considered to be promising adsorbent candidates because of their lost cost, wide availability, and high adsorption efficiency [14].

Halloysite $\left[\mathrm{Al}_{2} \mathrm{Si}_{2} \mathrm{O}_{5}(\mathrm{OH})_{4} \cdot 2 \mathrm{H}_{2} \mathrm{O}\right]$, a type of natural aluminosilicate clay mineral that is widely widespread in China [15], has a similar structure to kaolin, except that a monolayer of water molecules intercalates between the adjacent clay layers [16]. The sizes and polydispersity of halloysite depends on the specific geological deposit [17]. Halloysite nanotubes (HNTs) with negative charges on outer surface are a kind of outstanding hollow tubular material with an internal diameter of 20-30 nm and an external diameter from 30 to $70 \mathrm{~nm}[18,19]$, which exhibits excellent physical and chemical properties due to their large specific surface areas, abundant hydroxyl groups, porous structure, and great biocompatibility. HNTs are not toxic to humans [20,21], which represents a prerequisite for pharmaceutical and biomedical applications [22,23]. Most importantly, HNTs have been widely investigated as adsorbents for the removal of dyes and heavy metals in wastewater [24-26].

Herein, we used HNTs without any modification as adsorbent to investigate its natural adsorption performance toward CIP. The effects of various experiment conditions on adsorption capacity were thoroughly investigated, and $\mathrm{pH}$ value played an important role in regulating the adsorption efficiency. Furthermore, the adsorption kinetics and adsorption characteristics were discussed. The pseudo-second-order kinetic model fitted the data well and the equilibrium adsorption data were well described by the Langmuir isotherm model. It was found that the structure and surface property of HNTs were the key factors that affect the adsorption capacity toward CIP. It is also worth mentioning that the adsorbent HNTs could be efficiently reused for CIP adsorption for at least five cycles.

\section{Materials and Methods}

\subsection{Materials and Chemicals}

Ciprofloxacin $(\mathrm{CIP})$, sodium hydroxide $(\mathrm{NaOH})$, and hydrochloric acid $(\mathrm{HCl})$ were purchased from Aladdin Co. Methylene blue (MB), acid red 88 (AR 88), acid blue 9 (AB 9), rhodamine B (RhB), acid orange 3 (AO 3), and methyl orange (MO) were purchased from J\&K Scientific Ltd., Beijing, China. HNTs with purity of $98 \%$ were purchased from Wurun Material Technology Ltd., Guangzhou, China. The chemical compositions (\%) of HNTs are $\mathrm{SiO}_{2} 41.08, \mathrm{Al}_{2} \mathrm{O}_{3} 34.94, \mathrm{Fe}_{2} \mathrm{O}_{3}$ 0.30, $\mathrm{MgO} 0.18, \mathrm{CaO} 0.21$, $\mathrm{Na}_{2} \mathrm{O} 0.25, \mathrm{~K}_{2} \mathrm{O} 0.06, \mathrm{MnO} 0.05$, and $\mathrm{TiO}_{2}$ 0.20; loss on ignition 22.76 .

All the chemicals were used without further purification.

\subsection{Analysis and Characterization Methods}

The phase structure of the HNTs was recorded on a powder $\mathrm{X}$-ray diffractometer (EmpypeanPanalytical) (PANalytical, Holland, Almelo, The Netherlands) with $\mathrm{Cu}$ Ka radiation $(\lambda=0.15406 \mathrm{~nm})$, in which the generator voltage is $40 \mathrm{kV}$ and the electric current is $40 \mathrm{~mA}$. The detailed structure and morphology were observed by transmission electron microscopy (TEM) on a JEM-2010 apparatus with an acceleration voltage of $200 \mathrm{kV}$. Scanning electron microscopy (SEM) images were obtained on a Hitachi S-4800 apparatus with an acceleration voltage of $15 \mathrm{kV}$ and a working distance of $6100 \mu \mathrm{m}$ (Hitachi, Tokyo, Japan) Fourier transform infrared spectroscopy (FT-IR) was performed on a Bruker Tensor 27 spectrophotometer, the data were collected over the range of $500-4000 \mathrm{~cm}^{-1}$ using a $\mathrm{KBr}$ background. $\mathrm{N}_{2}$ adsorption-desorption isotherms were measured at $77 \mathrm{~K}$ using a Micromeritics ASAP 2020 system (Norcross, GA, USA) under liquid nitrogen temperature $\left(-196^{\circ} \mathrm{C}\right)$. Before the measurement, the halloysite was outgassed at $200{ }^{\circ} \mathrm{C}$ for $10 \mathrm{~h}$. The specific surface area $\left(\mathrm{S}_{\mathrm{BET}}\right)$ was calculated by the multiple-point Brunauer-Emmett-Teller (BET) method [27]. Zeta potential was conducted on a Malvern Instruments UK, Zetasizer Nano ZEN3600 (Malvern, Worcestershire,United Kingdom) at different $\mathrm{pH}$ values and the disposable folded capillary cells are used in this test. Quality control was performed by repeating the experiments three times and average data was reported. 


\subsection{Adsorption Tests}

The stock solution was obtained by dissolving $50 \mathrm{mg}$ of analytically pure CIP in $1 \mathrm{~L}$ distilled water to get an initial concentration of $50 \mathrm{mg} / \mathrm{L}$. The stock solution was further diluted with distilled water to get the desired concentrations. All batch adsorption experiments were carried out using beaker $(50 \mathrm{~mL})$ in a thermostatic magnetic stirring apparatus. The CIP concentration was determined by a UV-vis spectrophotometer at $277 \mathrm{~nm}$ (UV-750S, Jinhua, China).

The removal efficiency $(\%)$ and the adsorption capacity $\left(q_{t}\right)$ of HNTs were calculated as the following equations, respectively.

$$
\begin{gathered}
\text { Removal efficiency }(\%)=\frac{\left(C_{0}-C_{\mathrm{t}}\right)}{C_{0}} \times 100 \% \\
q_{\mathrm{t}}=\frac{\left(C_{0}-C_{\mathrm{t}}\right) V}{m}
\end{gathered}
$$

where $C_{0}(\mathrm{mg} / \mathrm{L})$ is the initial CIP concentration and $C_{\mathrm{t}}(\mathrm{mg} / \mathrm{L})$ is the CIP concentration at time $\mathrm{t} ; q_{t}$ is the adsorption capacity of per unit adsorbent at time $\mathrm{t}(\mathrm{mg} / \mathrm{g}) ; V$ is the volume of the CIP solution (L); and $m$ is the mass of HNTs (g).

The recyclability of HNTs was also conducted. After adsorption, $50 \mathrm{mg}$ of HNTs was added into the $50 \mathrm{~mL}$ of $\mathrm{NaOH}$ ethanol solution $(0.01 \mathrm{M})$, then stirred for $60 \mathrm{~min}$, and then centrifuged for $5 \mathrm{~min}$. Subsequently, the adsorbent (HNTs) was collected, washed thoroughly with water, and dried. The obtained powder was then used for adsorption in the next adsorption cycle.

The adsorption experiments of organic dyes are as follows. Taking Methylene blue (MB) as an example, $20 \mathrm{mg}$ of HNTs was added into $30 \mathrm{~mL}$ of MB $(20 \mathrm{mg} / \mathrm{L})$ with stirring for $90 \mathrm{~min}$ at room temperature. At certain time intervals, $3 \mathrm{~mL}$ of suspension was sampled and centrifuged. The concentrations of various organic dyes were measured by the UV-vis spectrophotometer.

\section{Results}

\subsection{Adsorption Characteristics of HNTs Toward CIP}

HNTs dosages varied from 0.01 to $0.05 \mathrm{~g}$ at an initial CIP concentration of $30 \mathrm{mg} / \mathrm{L}$ ( $30 \mathrm{~mL}$ ). As shown in Figure 1a, the removal efficiency of HNTs toward CIP increases with an increase of adsorbent dosage from 0.01 to $0.05 \mathrm{~g}$. It could be observed that the removal efficiency of CIP increases relatively rapidly when the HNTs dosage increases from 0.01 to $0.02 \mathrm{~g}$. This phenomenon could be attributed to the abundant increase of active surface sites in the process of CIP adsorption, which significantly enhances the adsorption capacity [28,29]. Based on comprehensive considering the removal efficiency and the commercial cost, $0.05 \mathrm{~g}$ is selected as the optimal dosage for HNTs and used in the subsequent experiments.

As displayed in Figure 1b, the adsorption efficiency of HNTs toward CIP was studied under different $\mathrm{pH}$ value conditions. The results indicate that the removal efficiency of $\mathrm{CIP}$ increases with $\mathrm{pH}$ value varying from 3.0 to 6.0 , and then decreases rapidly with further increases in the $\mathrm{pH}$ value. When the $\mathrm{pH}$ value reaches 11.0, HNTs show nearly no adsorption behavior toward CIP. The CIP molecules undergo protonation-deprotonation reactions in aqueous solution, which can form three species including cationic species $(\mathrm{pH}<5.9)$, zwitterionic species $(5.9<\mathrm{pH}<8.9)$, and anionic species $(\mathrm{pH}>8.9)$ [30]. Therefore, when $\mathrm{pH}$ value is less than 6.0, plenty of cationic species exist in solution, which is beneficial for CIP adsorption because of the electrostatic interactions. However, there would be an adsorption competition between $\mathrm{H}^{+}$and CIP cationic species, which resulted in the decreased adsorption efficiency. When $\mathrm{pH}$ value is greater than 9.0, the emergence of CIP anion species enhances the electrostatic repulsion between HNTs adsorbent and CIP molecules, leading to the decrease of CIP adsorption. In contrast, when $\mathrm{pH}$ value is between 6.0 and 9.0, CIP zwitterionic species play the dominant role in the solution and there is little adsorption competition and electrostatic repulsion referred above. Thus, the electrostatic interactions between negative HNTs and CIP zwitterionic 
species contribute the excellent adsorption efficiency. The above result is consistent with the results of Zeta potential. Zeta potential of HNTs declines with the increase of $\mathrm{pH}$ value, indicating that there are more negative charges in the surface of HNTs, which is unfavorable for adsorption. Based on the above discussion, the optimum adsorption efficiency of HNTs toward CIP is obtained when pH value is 6.0, which is selected for further study.
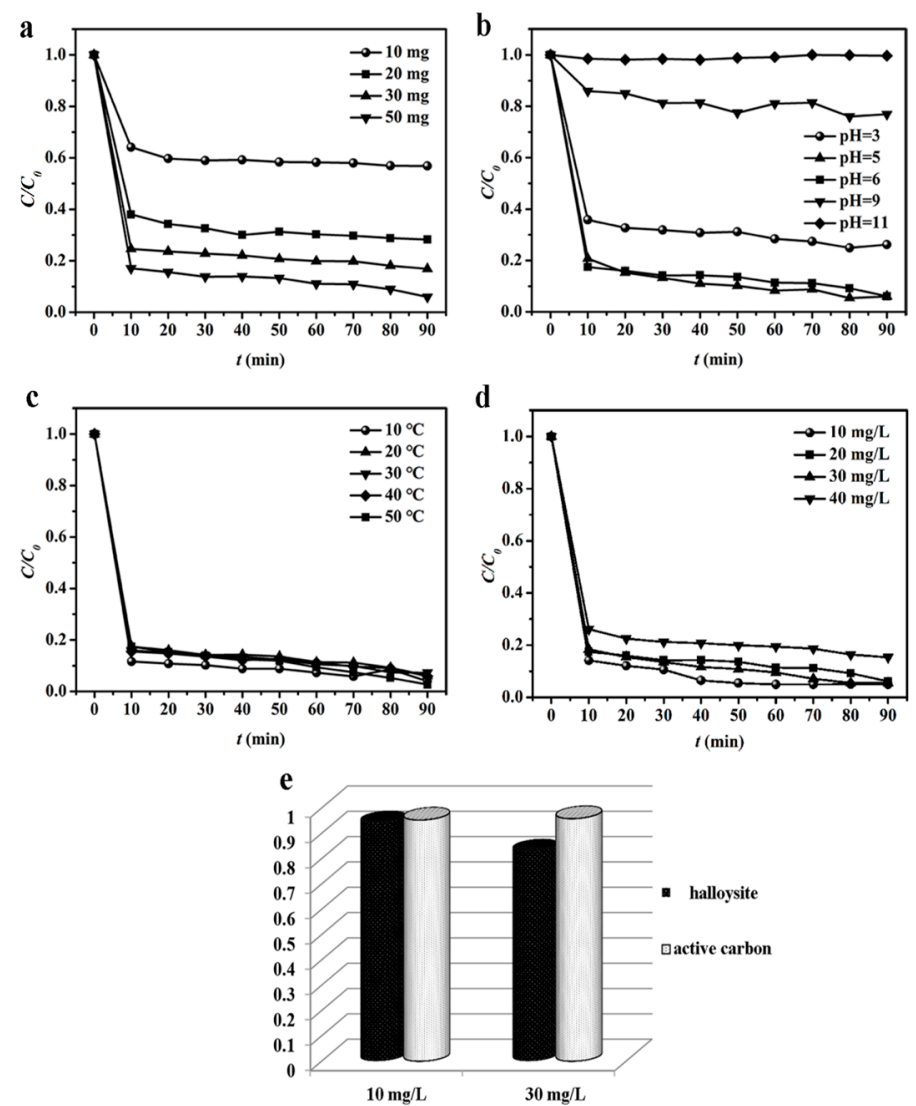

Figure 1. Effects of adsorbent dosage (a), $\mathrm{pH}$ value (b), temperature (c), and initial ciprofloxacin (CIP) concentration (d) on the adsorption efficiency of halloysite nanotubes (HNTs) toward CIP. The comparison of adsorption efficiencies between HNTs and active carbon at various CIP concentration (e).

Figure 1c shows the result of temperature effect on CIP adsorption efficiency over HNTs. As the temperature increases from $10^{\circ} \mathrm{C}$ to $50^{\circ} \mathrm{C}$, the adsorption process has not been accelerated or slowed down, which means that the adsorption process is irrespective of temperature. Thus, a nearby room temperature $20^{\circ} \mathrm{C}$ is chosen as the optimal condition for the following adsorption tests.

In order to investigate the effect of initial CIP concentration, batch experiments were performed by varying the CIP concentration from 10 to $40 \mathrm{mg} / \mathrm{L}$ (HNTs dosage $=50 \mathrm{mg}, \mathrm{pH}=6.0$, and temperature $=20^{\circ} \mathrm{C}$ ) (Figure $1 \mathrm{~d}$ ). In this study, the adsorption capacity of CIP increases from 5.70 to $20.32 \mathrm{mg} / \mathrm{g}$ with CIP concentration enhancing from 10 to $40 \mathrm{mg} / \mathrm{L}$. A high initial CIP concentration would produce a high driving force to urge CIP molecules to transfer to the HNTs surface, which could induce a higher adsorption capacity [31].

Based on the above adsorption experiments, the maximum adsorption capacity of HNTs toward $\mathrm{CIP}$ is optimized in the condition of adsorbent dosage $=0.05 \mathrm{~g}, \mathrm{pH}$ value $=5-6$, temperature $=20^{\circ} \mathrm{C}$, and the initial concentration of CIP $=30 \mathrm{mg} / \mathrm{L}$.

Moreover, the adsorption efficiency of active carbon toward CIP was also studied and the adsorption efficiency comparison between HNTs and active carbon was displayed in Figure 1e. 
It could be observed that HNTs display the equivalent adsorption efficiency in comparison with active carbon at lower CIP concentration, but little poorer adsorption efficiency than active carbon at higher CIP concentration.

It has been widely proposed that fast adsorption kinetics play an important role in the adsorption efficiency for an adsorbent [32-34]. To further investigate the adsorption kinetics, pseudo-first-order and pseudo-second-order kinetics models were adopted to analyze the adsorption process of CIP on HNTs and the obtained data are summarized in Table 1. The pseudo-first-order and pseudo-second-order kinetics models are expressed in Equations (3) and (4), respectively.

$$
\begin{gathered}
\ln \left(q_{\mathrm{e}}-q_{\mathrm{t}}\right)=\ln q_{\mathrm{e}}-k_{1} t \\
\frac{t}{q_{\mathrm{t}}}=\frac{1}{k_{2} q_{e}^{2}}+\frac{1}{q_{\mathrm{e}}} t
\end{gathered}
$$

where $q_{\mathrm{e}}(\mathrm{mg} / \mathrm{g})$ and $q_{\mathrm{t}}(\mathrm{mg} / \mathrm{g})$ are the adsorption capacity at equilibrium and at time $t$, respectively; $k_{1}\left(\mathrm{~min}^{-1}\right)$ is the pseudo-first-order rate constant; and $k_{2}(\mathrm{~g} /(\mathrm{mg} \cdot \mathrm{min}))$ is the pseudo-second-order rate constant, respectively.

The adsorption kinetics of HNTs toward CIP is presented in Figure 2. As shown in Figure 2a, the adsorbed data does not fit well with the pseudo-first-order kinetic model $\left(R^{2}<0.90\right)$. In contrast, the pseudo-second-order rate equation for CIP adsorption onto HNTs has a better fit with high $R^{2}$ value. Related parameters are given in Table 1 . Three steps are included in adsorption kinetics [35,36]: (i) the CIP molecules diffuse from liquid phase to a liquid-solid interface; (ii) the CIP molecules move from a liquid-solid interface to solid surfaces; and (iii) the CIP molecules diffuse onto the surface of HNTs [37].
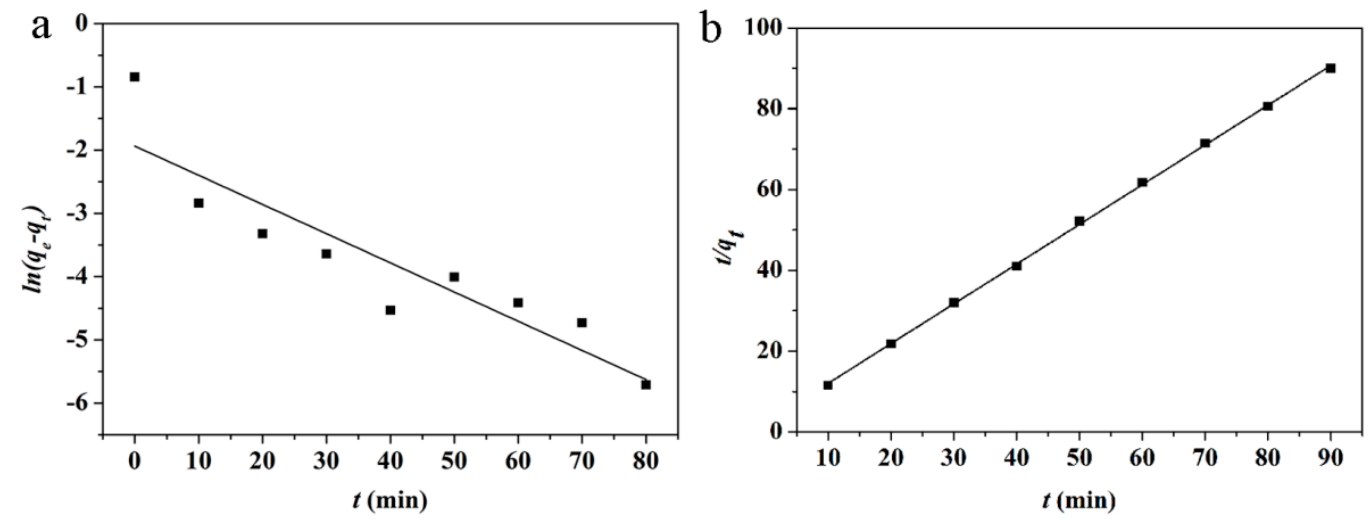

Figure 2. Pseudo-first-order (a) and pseudo-second-order (b) for CIP adsorption onto HNTs.

Two main isotherm models including the Langmuir model (LM) and Freundlich model (FM) are generally used to determine the equilibrium relationship between the adsorbent and the adsorbate molecules. LM adsorption isotherm indicates that adsorption takes place at specific active sites of the adsorbent and has found successful application for many adsorption processes of monolayer adsorption [38]. The linear form of LM is described as follows.

Table 1. Kinetic parameters for the pseudo-first-order and pseudo-second-order models.

\begin{tabular}{lcccc}
\hline \multirow{2}{*}{ Kinetic Model } & \multicolumn{4}{c}{ Parameters } \\
\cline { 2 - 5 } & $\left.\boldsymbol{k}_{\mathbf{1}}\left(\mathbf{m i n}^{-\mathbf{1}}\right) / \boldsymbol{k}_{\mathbf{2}}(\mathrm{g} / \mathbf{( m g} \cdot \mathbf{m i n})\right)$ & $\boldsymbol{q}_{\mathrm{e}}(\mathbf{m g} / \mathbf{g})$ & $\boldsymbol{R}^{\mathbf{2}}$ & Fitting Error \\
\hline Pseudo-first-order & 0.0462 & 0.1443 & 0.80626 & 0.00788 \\
Pseudo-second-order & 0.4342 & 1.0172 & 0.99955 & 0.00735 \\
\hline
\end{tabular}




$$
\frac{C_{\mathrm{e}}}{q_{\mathrm{e}}}=\frac{1}{k q_{\max }}+\frac{1}{q_{\max }} C_{\mathrm{e}}
$$

where $k$ is rate of the adsorption; $C_{\mathrm{e}}(\mathrm{mg} / \mathrm{L})$ is the equilibrium concentration of the CIP molecules; and $q_{\max }(\mathrm{mg} / \mathrm{g})$ and $q_{\mathrm{e}}(\mathrm{mg} / \mathrm{g})$ is maximum adsorption capacity and the amount of adsorbed CIP per unit mass of adsorbent at equilibrium, respectively.

The FM adsorption isotherm illustrates the surface heterogeneity and represents that the adsorption occurs at various sites with different adsorption energy. It is expressed by the following equation.

$$
\log q_{\mathrm{e}}=\log k_{\mathrm{F}}+\frac{1}{n} \log C_{\mathrm{e}}
$$

where $k_{\mathrm{F}}$ is Freundlich adsorbent capacity $(\mathrm{L} / \mathrm{mg})$ and $\mathrm{n}$ is the reciprocal of reaction order.

The linear plots of Langmuir and Freundlich adsorption isotherms are displayed in Figure 3. The Langmuir model has a better fit for CIP adsorption on HNTs $\left(R^{2}>0.96\right)$ than the Freundlich model, indicating that the adsorption process of CIP on HNTs is a monolayer adsorption. The values of $q_{\max }$ and $k$ are calculated from the slope and the intercept of the plots using Equation (5). The Langmuir and Freundlich parameters are given in Table 2.
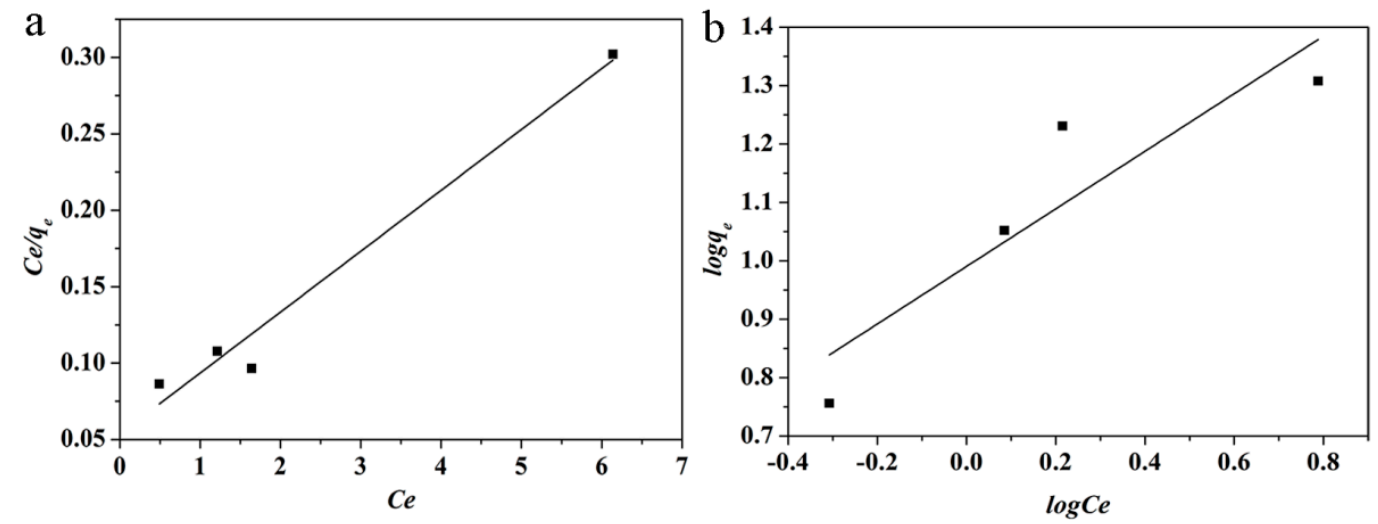

Figure 3. The linearized Langmuir (a) and Freundlich isotherm (b) for adsorption CIP on HNTs.

Table 2. Parameters for the Langmuir and Freundlich models. HNTs—halloysite nanotubes.

\begin{tabular}{ccccc}
\hline Isotherm Model & & \multicolumn{2}{c}{ Parameters } \\
\hline Langmuir model & $q_{\max }(\mathrm{mg} / \mathrm{g})$ & $k(\mathrm{~L} / \mathrm{mg})$ & $R^{2}$ & fitting error \\
HNTs & 25.09 & 0.7425 & 0.96564 & 0.00431 \\
Freundlich model & $k_{\mathrm{F}}(\mathrm{L} / \mathrm{mg})$ & $1 / \mathrm{n}$ & $R^{2}$ & fitting error \\
HNTs & 2.69 & 0.4927 & 0.74749 & 0.15675 \\
\hline
\end{tabular}

Table S1 displays the $q_{\max }$ values of HNTs and other clays toward CIP. It is obvious that the $q_{\max }$ value of HNTs is much higher than kaolinite $(6.99 \mathrm{mg} / \mathrm{g})$, aluminum hydrous oxide $(14.72 \mathrm{mg} / \mathrm{g})$, and even modified coal fly ash $(1.547 \mathrm{mg} / \mathrm{g})$, but still lower than montmorillonite and bentonite. Moreover, this value is much lower than activated carbon and other modified adsorbents, because larger specific surface area and modification are favorable for improving the adsorption capacity [39,40].

\subsection{Adsorbent Characterization}

The XRD patterns of HNTs before and after adsorption are presented in Figure S1. The sharp peak at $2 \theta=12.0^{\circ}$ is the typical diffraction peak (001) of HNTs. Moreover, the reflection peak at $19.9^{\circ}$ and $25^{\circ}$ are characteristic peaks of tubular HNTs [41]. In comparison with XRD pattern of HNTs 
before adsorption, no significant change could be markedly observed for main reflections of HNTs after adsorption, which demonstrates the outstanding stability of HNTs. Moreover, CIP exists as CIP molecules other than CIP crystal phase on the surface of HNTs after adsorption, thus no XRD pattern for CIP could be observed.

The FT-IR spectra of HNTs before and after CIP adsorption are shown in Figure 4. For HNTs, the peaks at 3701 and $3626 \mathrm{~cm}^{-1}$ are ascribed to the stretching vibrations of inner-surface hydroxyl groups [42]. Interlayer water is indicated by the deformation vibration at $1631 \mathrm{~cm}^{-1}$. The band at $1105 \mathrm{~cm}^{-1}$ is attributed to the stretching mode of apical Si-O, while the band at $1006 \mathrm{~cm}^{-1}$ is assigned to the stretching vibrations of Si-O-Si. The band at $910 \mathrm{~cm}^{-1}$ is deformation vibration of $\mathrm{Al}-\mathrm{OH}$. The band observed at $554 \mathrm{~cm}^{-1}$ is assigned to Al-O-Si vibration. For CIP, the bands at 3520 and $3436 \mathrm{~cm}^{-1}$ are assigned to hydroxyl and $\mathrm{N}-\mathrm{H}$ groups [43], respectively. The bands located at 1714,1621 , and $1270 \mathrm{~cm}^{-1}$ belong to $\mathrm{C}=\mathrm{O}, \mathrm{C}=\mathrm{C}$, and $\mathrm{C}-\mathrm{N}$ band [43-45], respectively. After CIP adsorption, the band assigned to $\mathrm{N}-\mathrm{H}$ vibration $\left(3436 \mathrm{~cm}^{-1}\right)$ for $\mathrm{CIP}$ emerges and the intensity becomes stronger with prolonging the adsorption time. Two new bands at 1492 and $1380 \mathrm{~cm}^{-1}$ belonged to deformation $\mathrm{C}-\mathrm{H}_{2}$ vibration in CIP [46] could be obviously observed after adsorption for $10 \mathrm{~min}$. Moreover, the bands related to hydroxyl groups for HNTs remains entirely unchanged, indicating that the adsorption of CIP onto HNTS is physical adsorption [47].

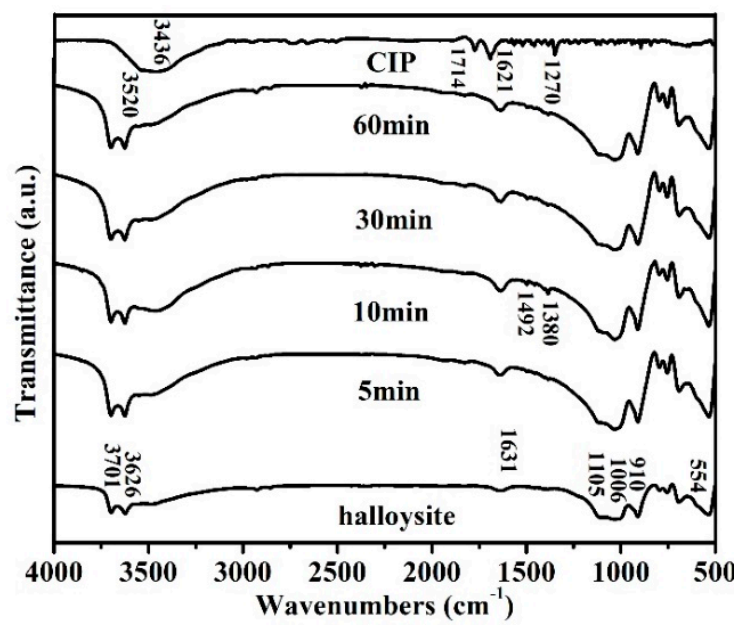

Figure 4. Fourier transform infrared spectroscopy (FT-IR) spectra of HNTs before and after CIP adsorption.

Morphology and size of HNTs have an important influence on their property [48,49]. Scanning electron microscopy was used to observe the morphologies of HNTs before and after CIP adsorption and the results are shown in Figure 5. Figure 5a,b display the morphology of HNTs before CIP adsorption. HNTs display tubular morphology with smooth surface as well as high dispersion and relative regularity in morphology and diameter. The length and diameter of HNTs range from 0.2 1.7 $\mu \mathrm{m}$ and 40 70 nm, respectively. After CIP adsorption, the HNTs still remain original tubular structure and there is no change in distribution and diameter. However, the surface morphology of HNTs undergoes great changes after CIP adsorption. As clearly displayed in Figure 6d, the surface of HNTs becomes rough and defective after CIP adsorption.

Do the CIP molecules have the effect on the surface morphology of HNTs? To explore this phenomenon, the contrast experiment in which HNTs were immersed in deionized water without CIP molecules for 90 min was processed and the related SEM images are shown in Figure S2. It could be clearly observed that the surface of HNTs also became rough and defective after immersion in deionized water. Thus, the surface roughness and defects of HNTs are not related to CIP molecules. Do the generation of surface roughness and defects contribute to the adsorption behavior of CIP on 
HNTs? Then, another contrast test that the adsorption efficiency of HNTs after immersion in deionized water for $90 \mathrm{~min}$ was analyzed and the results are displayed in Figure S3. The results obtained from Figure S3 indicate that the immersion in deionized water nearly has no effect on the adsorption efficiency of HNTs.

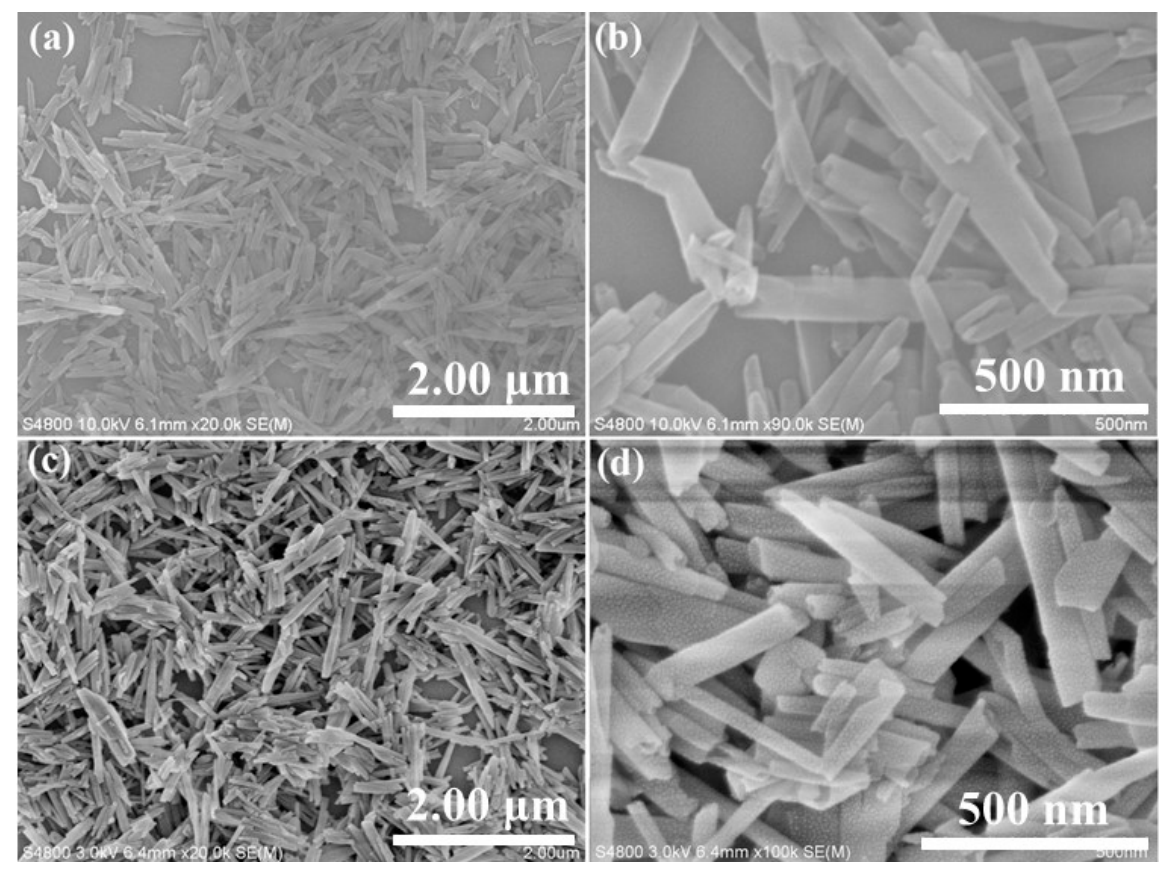

Figure 5. Scanning electron microscopy (SEM) images of HNTs before $(\mathbf{a}, \mathbf{b})$ and after $(\mathbf{c}, \mathbf{d})$ CIP adsorption.

TEM technique was also employed to further check the structure of the HNTs before and after CIP adsorption. Figure $6 \mathrm{a}, \mathrm{b}$ present the morphology of HNTs before adsorption. It can be observed that HNTs consist of a transparent central area as tubular. The internal diameter and length of HNTs range from 20-30 $\mathrm{nm}$ and 0.2-1.7 $\mu \mathrm{m}$, respectively, and the shell thickness of HNTs is about 15-20 nm. As displayed in Figure 6c, HNTs still maintain their original structure after adsorption. In Figure 6d, it is noteworthy that the surface of HNTs becomes rough and defective after CIP adsorption, which is consistent with the SEM result. 


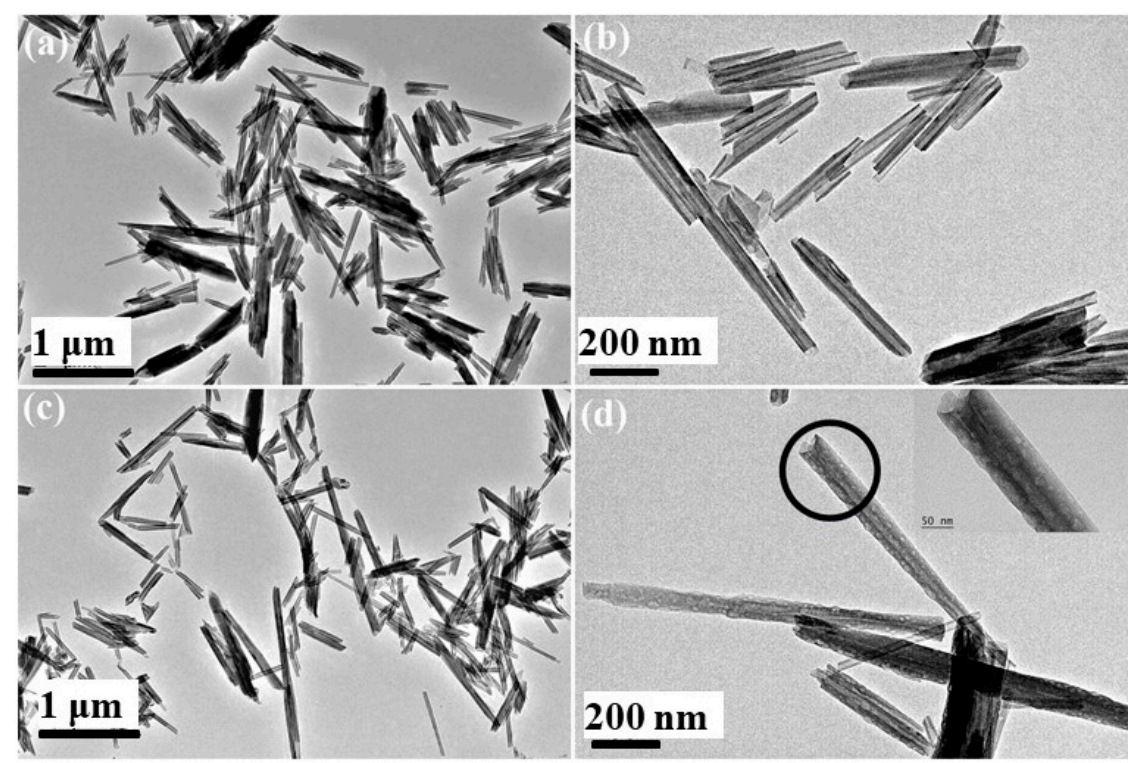

Figure 6. Transmission electron microscopy (TEM) images of HNTs before $(\mathbf{a}, \mathbf{b})$ and after $(\mathbf{c}, \mathbf{d})$ CIP adsorption.

Figure 7 shows the $\mathrm{N}_{2}$ adsorption-desorption isotherms of HNTs before and after adsorption. The curves are approaching to type IV isotherm, indicating the presence of mesopores. The specific surface areas of HNTs before and after adsorption are 45.48 and $46.76 \mathrm{~m}^{2} / \mathrm{g}$, respectively. After adsorption, CIP exists as CIP molecules other than CIP crystal phase on the surface of HNTs, thus the CIP adsorption has little impact on the specific surface area of HNTs.

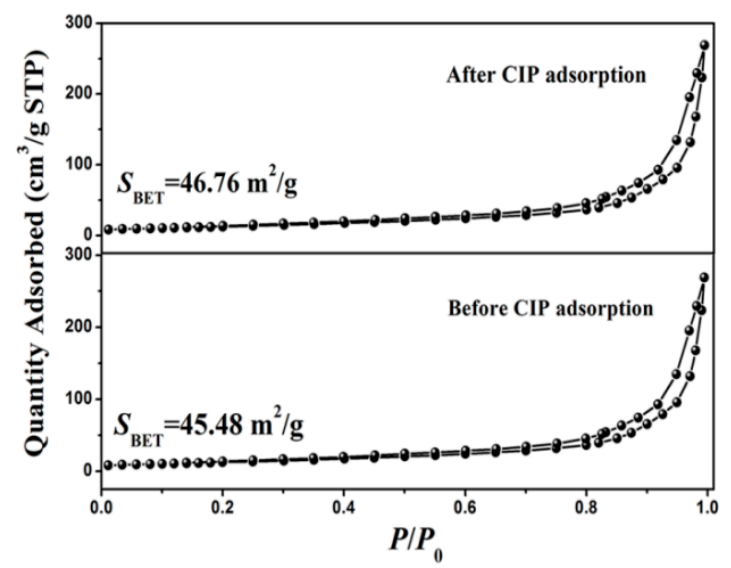

Figure 7. $\mathrm{N}_{2}$ adsorption-desorption isotherm of HNTs before and after adsorption.

Based on the fact that HNTs is an efficient adsorbent toward CIP, it is necessary to study the adsorption stability of the HNTs toward CIP. In the cycle experiment, the adsorption efficiency of HNTs could still maintain 95\% after five cycles (Figure 8). The excellent stability of HNTs implies its promising application in CIP removal. 


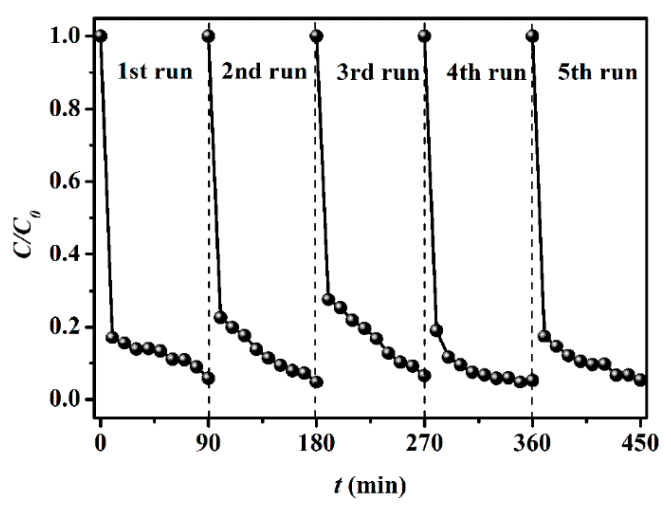

Figure 8. The recycle tests of HNTs as adsorbent for CIP removal.

\section{Discussion}

There are possibly two aspects that contribute to the excellent adsorption efficiency of HNTs: one is the large surface area and the other is the electrostatic attraction between HNTs and CIP molecules. A large surface area could provide lots of readily available adsorption sites for CIP molecules. The sites have a profound effect on the properties and stability of HNTs [50]. Electrostatic attraction could provide a driving force to lead a fast diffusion and rapid equilibrium attainment.

Surface charge magnitude is extremely important for an adsorbent, and always should be referred when discussing the adsorption mechanism. Zeta potential measurement is a general method for identifying the surface charge magnitude. Figure 9 shows the zeta potential of HNTs before and after CIP adsorption at various $\mathrm{pH}$ values. As indicated in Figure 9, the surface of HNTs is negatively charged among the $\mathrm{pH}$ value of 2-12. Moreover, the surface charge becomes more negative with increasing the $\mathrm{pH}$ value. It can be deduced from Figures $1 \mathrm{~b}$ and 9 that when $\mathrm{pH}$ value is lower than 6.0, the adsorption efficiency of HNTs increases with enhancing the $\mathrm{pH}$ value. In this adsorption process, electrostatic attraction is predominantly responsible for the high adsorption efficiency of HNTs and the decreased adsorption efficiency at $\mathrm{pH}=3.0$ may be related to the adsorption competition between large amount of $\mathrm{H}^{+}$and CIP cationic species. When $\mathrm{pH}$ value is higher than 9.0, the electrostatic repulsion between HNTs adsorbent and CIP anionic molecules results in poor adsorption efficiency. When $\mathrm{pH}$ value is between 6.0 and 9.0, the electrostatic attraction also plays the dominant role because of less adsorption competition and electrostatic repulsion in the adsorption process. After CIP adsorption, the zeta potential of HNTs is apparently positively enhanced and even positively charged among $\mathrm{pH}$ value of 2-6, demonstrating the efficient adsorption of CIP molecules onto the surface of HNTs. This result further confirms that the electrostatic attraction between HNTs and CIP molecules plays a vital role in the adsorption process [50-52].

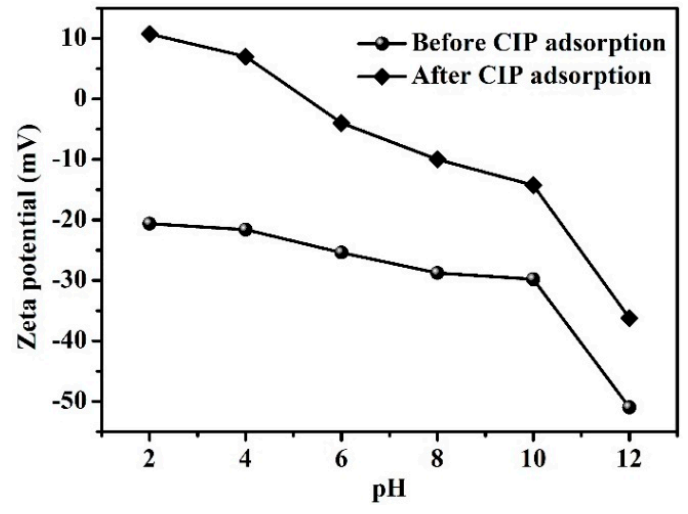

Figure 9. Zeta potential of HNTs in different $\mathrm{pH}$ condition. 
For confirming this deduction, six organic dyes including positively charged dyes and negatively charged dyes are chosen to take adsorption experiments. As shown in Figure 10a, cationic dyes Methylene blue (MB) and Acid red 88 (AR 88) could be almost completely adsorbed by HNTs and Acid blue 9 (AB 9), as well as Rhodamine B (RhB), could be mostly adsorbed by HNTs. In contrast, there is very low adsorption efficiency for anionic dyes Methyl orange (MO) and Acid orange 3 ( $\mathrm{AO} 3$ ). The adsorption of four cationic dyes on HNTs is very rapid and could reach the maximum removal efficiency almost within $10 \mathrm{~min}$ (Figure S4). The actual industrial dye wastewater is usually composed of more than one kind of dyes. Therefore, a series of mixed dye solutions is prepared to examine the adsorption performance of HNTs adsorbent. Figure 10b displays the selective adsorption performances of HNTs toward mixed dye solutions. The result reveals that HNTs displays excellent selective adsorption performance toward cationic dyes in the mixed dye solutions.
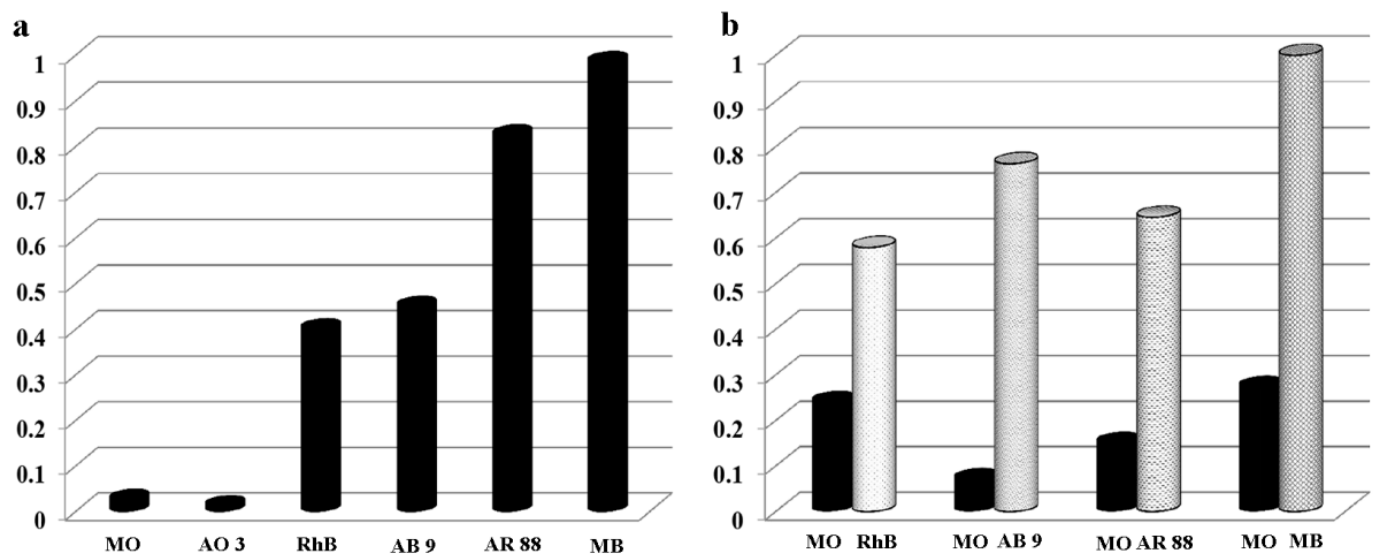

Figure 10. The adsorption histogram of HNTs toward various separate organic dyes (a) and mixed dyes (b).

\section{Conclusions}

In summary, we explored an efficient and low-cost adsorbent for the adsorption of CIP. Various conditions were investigated and $\mathrm{pH}$ value was found to be an important role in regulating the adsorption efficiency of HNTs. The $q_{\max }(25.09 \mathrm{mg} / \mathrm{g})$ value was optimized in the condition of adsorbent dosage $=0.05 \mathrm{~g}, \mathrm{pH}$ value $=5-6$, temperature $=20^{\circ} \mathrm{C}$, and the initial concentration of $\mathrm{CIP}=30 \mathrm{mg} / \mathrm{L}$. Furthermore, the structure and surface properties of HNTs were the key factors that affect the adsorption capacities for CIP. The pseudo-second-order kinetic model fitted the adsorption data very well and the equilibrium adsorption data were well described by the Langmuir isotherm model. Most importantly, the adsorbent HNTs could be efficiently regenerated and reused for CIP adsorption over five cycles. High stability, low cost, and wide availability imply the potential applications for HNTs in wastewater treatment.

Supplementary Materials: The following are available online at http://www.mdpi.com/2075-163X/8/9/387/s1. Table S1: The $q_{\text {max }}$ values of HNTs and other clays toward CIP adsorption, Figure S1: XRD patterns of HNTs before and after CIP adsorption, Figure S2: SEM images of HNTs immersed in deionized water without CIP molecules for 90 min, Figure S3: The adsorption efficiency of HNTs toward CIP after HNTs immersed in deionized water for $90 \mathrm{~min}$. The insert graph is the comparison of adsorption efficiencies of HNTs (1-without immersion in deionized water; 2-with immersion in deionized water), Figure S4: The adsorption efficiency of HNTs toward various cationic organic dyes.

Author Contributions: C.D. received the project and designed the experiment; R.C. performed the experiment; R.C., H.L., and Z.L analyzed the data; R.C. and C.D. wrote and revised the manuscript, respectively.

Acknowledgments: This work was supported by the National Natural Science Foundation of China (NSFC, 51462025 and 51764042) and Opening Project of Hunan Key Laboratory of Mineral Materials and Application (MMA 201702).

Conflicts of Interest: The authors declare no conflict of interest. 


\section{References}

1. Van Stelten, J.; Silva, F.; Belin, D.; Silhavy, T.J. Effects of antibiotics and a proto-oncogene homolog on destruction of protein translocator secy. Science 2009, 325, 753. [CrossRef] [PubMed]

2. Ji, Y.; Shi, Y.; Dong, W.; Wen, X.; Jiang, M.; Lu, J. Thermo-activated persulfate oxidation system for tetracycline antibiotics in degradation aqueous solution. Chem. Eng. J. 2016, 298, 225-233. [CrossRef]

3. Bu, Q.; Wang, B.; Huang, J.; Deng, S.; Yu, G. Pharmaceuticals and personal care products in the aquatic environment in China: A review. J. Hazard. Mater. 2013, 262, 189-211. [CrossRef] [PubMed]

4. Liu, J.L.; Wong, M.H. Pharmaceuticals and personal care products (PPCPs): A review on environmental contamination in China. Environ. Int. 2013, 59, 208-224. [CrossRef] [PubMed]

5. Ebert, I.; Bachmann, J.; Kuhnen, U.; Kuster, A.; Kussatz, C.; Maletzki, D.; Schluter, C. Toxicity of the fluoroquinolone antibiotics enrofloxacin and ciprofloxacin to photoautotrophic aquatic organisms. Environ. Toxicol. Chem. 2011, 30, 2786-2792. [CrossRef] [PubMed]

6. Van Doorslaer, X.; Dewulf, J.; Van Langenhove, H.; Demeestere, K. Fluoroquinolone antibiotics: An emerging class of environmental micropollutants. Sci. Total Environ. 2014, 500-501, 250-269. [CrossRef] [PubMed]

7. Zhang, Q.Q.; Ying, G.G.; Pan, C.G.; Liu, Y.S.; Zhao, J.L. Comprehensive evaluation of antibiotics emission and fate in the river basins of China: Source analysis, multimedia modeling, and linkage to bacterial resistance. Environ. Sci. Technol. 2015, 49, 6772-6782. [CrossRef] [PubMed]

8. Hong, Y.; Li, C.; Zhang, G.; Meng, Y.; Yin, B.; Zhao, Y.; Shi, W. Efficient and stable $\mathrm{Nb}_{2} \mathrm{O}_{5}$ modified g- $\mathrm{C}_{3} \mathrm{~N}_{4}$ photocatalyst for removal of antibiotic pollutant. Chem. Eng. J. 2016, 299, 74-84. [CrossRef]

9. Meng, F.; Gao, G.; Yang, T.T.; Chen, X.; Chao, Y.; Na, G.; Ge, L.; Huang, L.N. Effects of fluoroquinolone antibiotics on reactor performance and microbial community structure of a membrane bioreactor. Chem. Eng. J. 2015, 280, 448-458. [CrossRef]

10. Babel, S.; Kurniawan, T.A. Low-cost adsorbents for heavy metals uptake from contaminated water: A review. J. Hazard. Mater. 2003, 97, 219-243. [CrossRef]

11. Bhattacharyya, K.G.; Gupta, S.S. Adsorption of a few heavy metals on natural and modified kaolinite and montmorillonite: A review. Adv. Colloid Interfac. 2008, 140, 114-131. [CrossRef] [PubMed]

12. Puanngam, M.; Unob, F. Preparation and use of chemically modified MCM-41 and silica gel as selective adsorbents for $\mathrm{Hg}$ (II) ions. J. Hazard. Mater. 2008, 154, 578-587. [CrossRef] [PubMed]

13. Wan Ngah, W.S.; Hanafiah, M.A.K.M. Removal of heavy metal ions from wastewater by chemically modified plant wastes as adsorbents: A review. Bioresour. Technol. 2008, 99, 3935-3948. [CrossRef] [PubMed]

14. Manohar, D.M.; Noeline, B.F.; Anirudhan, T.S. Adsorption performance of Al-pillared bentonite clay for the removal of cobalt (II) from aqueous phase. Appl. Clay Sci. 2006, 31, 194-206. [CrossRef]

15. Lvov, Y.; Wang, W.; Zhang, L.; Fakhrullin, R. Halloysite clay nanotubes for loading and sustained release of functional compounds. Adv. Mater. 2016, 28, 1227-1250. [CrossRef] [PubMed]

16. Yang, Y.; Chen, Y.; Leng, F.; Huang, L.; Wang, Z.; Tian, W. Recent advances on surface modification of halloysite nanotubes for multifunctional applications. Appl. Sci. 2017, 7, 1215. [CrossRef]

17. Cavallaro, G.; Chiappisi, L.; Pasbakhsh, P.; Gradzielski, M.; Lazzara, G. A structural comparison of halloysite nanotubes of different origin by small-angle neutron scattering (SANS) and electric birefringence. Appl. Clay Sci. 2018, 160, 71-80. [CrossRef]

18. Lvov, Y.M.; Shchukin, D.G.; Möhwald, H.; Price, R.R. Halloysite clay nanotubes for controlled release of protective agents. ACS Nano 2008, 2, 814-820. [CrossRef] [PubMed]

19. Cavallaro, G.; Danilushkina, A.A.; Evtugyn, G.V.; Lazzara, G.; Milioto, S.; Parisi, F.; Rozhina, V.E.; Fakhrullin, F.R. Halloysite nanotubes: Controlled access and release by smart gates. Nanomaterials 2017, 7, 199. [CrossRef] [PubMed]

20. Wang, X.; Gong, J.; Rong, R.; Gui, Z.; Hu, T.; Xu, X. Halloysite nanotubes-induced al accumulation and fibrotic response in lung of mice after 30-day repeated oral administration. J. Agric. Food Chem. 2018, 66, 2925-2933. [CrossRef] [PubMed]

21. Stavitskaya, A.V.; Novikov, A.A.; Kotelev, M.S.; Kopitsyn, D.S.; Rozhina, E.V.; Ishmukhametov, I.R.; Fakhrullin, R.F.; Ivanov, E.V.; Lvov, Y.M.; Vinokurov, V.A. Fluorescence and cytotoxicity of cadmium sulfide quantum dots stabilized on clay nanotubes. Nanomaterials 2018, 8, 391. [CrossRef] [PubMed] 
22. Cavallaro, G.; Lazzara, G.; Milioto, S.; Parisi, F.; Evtugyn, V.; Rozhina, E.; Fakhrullin, R. Nanohydrogel formation within the halloysite lumen for triggered and sustained release. ACS Appl. Mater. Interfaces 2018, 10, 8265-8273. [CrossRef] [PubMed]

23. Lazzara, G.; Cavallaro, G.; Panchal, A.; Fakhrullin, R.; Stavitskaya, A.; Vinokurov, V.; Lvov, Y. An assembly of organic-inorganic composites using halloysite clay nanotubes. Curr. Opin. Colloid Interface Sci. 2018, 35, 42-50. [CrossRef]

24. He, Q.; Yang, D.; Deng, X.; Wu, Q.; Li, R.; Zhai, Y.; Zhang, L. Preparation, characterization and application of $\mathrm{N}$-2-pyridylsuccinamic acid-functionalized halloysite nanotubes for solid-phase extraction of $\mathrm{Pb}(\mathrm{II})$. Water Res. 2013, 47, 3976-3983. [CrossRef] [PubMed]

25. Moslehyani, A.; Mobaraki, M.; Ismail, A.F.; Matsuura, T.; Hashemifard, S.A.; Othman, M.H.D.; Mayahi, A.; Rezaei DashtArzhandi, M.; Soheilmoghaddam, M.; Shamsaei, E. Effect of HNTs modification in nanocomposite membrane enhancement for bacterial removal by cross-flow ultrafiltration system. React. Funct. Polym. 2015, 95, 80-87. [CrossRef]

26. Vergaro, V.; Abdullayev, E.; Lvov, Y.M.; Zeitoun, A.; Cingolani, R.; Rinaldi, R.; Leporatti, S. Cytocompatibility and uptake of halloysite clay nanotubes. Biomacromolecules 2010, 11, 820-826. [CrossRef] [PubMed]

27. Rouquerol, J.; Llewellyn, P.; Rouquerol, F. Is the bet equation applicable to microporous adsorbents? Stud. Surf. Sci. Catal. 2007, 160, 49-56.

28. Angar, Y.; Djelali, N.E.; Kebbouche-Gana, S. Investigation of ammonium adsorption on Algerian natural bentonite. Environ. Sci. Pollut. Res. 2017, 24, 11078-11089. [CrossRef] [PubMed]

29. Saltalı, K.; Sarı, A.; Aydın, M. Removal of ammonium ion from aqueous solution by natural Turkish (yıldızeli) zeolite for environmental quality. J. Hazard. Mater. 2007, 141, 258-263. [CrossRef] [PubMed]

30. Li, S.; Zhang, X.; Huang, Y. Zeolitic imidazolate framework-8 derived nanoporous carbon as an effective and recyclable adsorbent for removal of ciprofloxacin antibiotics from water. J. Hazard. Mater. 2017, 321, 711-719. [CrossRef] [PubMed]

31. Calagui, M.J.C.; Senoro, D.B.; Kan, C.C.; Salvacion, J.W.L.; Futalan, C.M.; Wan, M.W. Adsorption of indium (III) ions from aqueous solution using chitosan-coated bentonite beads. J. Hazard. Mater. 2014, 277, 120-126. [CrossRef] [PubMed]

32. Alshameri, A.; Ibrahim, A.; Assabri, A.M.; Lei, X.; Wang, H.; Yan, C. The investigation into the ammonium removal performance of yemeni natural zeolite: Modification, ion exchange mechanism, and thermodynamics. Powder Technol. 2014, 258, 20-31. [CrossRef]

33. Mohammadi, N.; Khani, H.; Gupta, V.K.; Amereh, E.; Agarwal, S. Adsorption process of methyl orange dye onto mesoporous carbon material-kinetic and thermodynamic studies. J. Colloid Interfce Sci. 2011, 362, 457-462. [CrossRef] [PubMed]

34. Xia, P.; Wang, X.; Wang, X.; Song, J.; Wang, H.; Zhang, J.; Zhao, J. Struvite crystallization combined adsorption of phosphate and ammonium from aqueous solutions by mesoporous MgO-loaded diatomite. Colloids Surf. A: Physicochem. Eng. Asp. 2016, 506, 220-227. [CrossRef]

35. Liao, P.; Yuan, S.; Xie, W.; Zhang, W.; Tong, M.; Wang, K. Adsorption of nitrogen-heterocyclic compounds on bamboo charcoal: Kinetics, thermodynamics, and microwave regeneration. J. Colloid Interf. Sci. 2013, 390, 189-195. [CrossRef] [PubMed]

36. Uğurlu, M.; Karaoğlu, M.H. Adsorption of ammonium from an aqueous solution by fly ash and sepiolite: Isotherm, kinetic and thermodynamic analysis. Microporous Mesoporous Mater. 2011, 139, 173-178. [CrossRef]

37. Sheela, T.; Nayaka, Y.A.; Viswanatha, R.; Basavanna, S.; Venkatesha, T.G. Kinetics and thermodynamics studies on the adsorption of $\mathrm{Zn}(\mathrm{II}), \mathrm{Cd}(\mathrm{II})$ and $\mathrm{Hg}(\mathrm{II})$ from aqueous solution using zinc oxide nanoparticles. Powder Technol. 2012, 217, 163-170. [CrossRef]

38. Unuabonah, E.I.; Adebowale, K.O.; Olu-Owolabi, B.I.; Yang, L.Z.; Kong, L.X. Adsorption of Pb (II) and Cd (II) from aqueous solutions onto sodium tetraborate-modified kaolinite clay: Equilibrium and thermodynamic studies. Hydrometallurgy 2008, 93, 1-9. [CrossRef]

39. Tyagi, U.; Anand, N.; Kumar, D. Synergistic effect of modified activated carbon and ionic liquid in the conversion of microcrystalline cellulose to 5-hydroxymethyl furfural. Bioresour. Technol. 2018, 267, 326-332. [CrossRef] [PubMed]

40. Olusegun, S.J.; de Sousa Lima, L.F.; Mohallem, N.D.S. Enhancement of adsorption capacity of clay through spray drying and surface modification process for wastewater treatment. Chem. Eng. J. 2018, 334, 1719-1728. [CrossRef] 
41. Deng, S.; Zhang, J.; Ye, L.; Wu, J. Toughening epoxies with halloysite nanotubes. Polymer 2008, 49, 5119-5127. [CrossRef]

42. Luo, P.; Zhao, Y.; Zhang, B.; Liu, J.; Yang, Y.; Liu, J. Study on the adsorption of neutral red from aqueous solution onto halloysite nanotubes. Water Res. 2009, 44, 1489-1497. [CrossRef] [PubMed]

43. Silva, L.S.; Ferreira, F.J.L.; Silva, M.S.; Citó, A.M.G.L.; Meneguin, A.B.; Sábio, R.M.; Barud, H.S.; Bezerra, R.D.S.; Osajima, J.A.; Silva Filho, E.C. Potential of amino-functionalized cellulose as an alternative sorbent intended to remove anionic dyes from aqueous solutions. Int. J. Biol. Macromol. 2018, 116, 1282-1295. [CrossRef] [PubMed]

44. Xie, A.; Dai, J.; Chen, X.; Ma, P.; He, J.; Li, C.; Zhou, Z.; Yan, Y. Ultrahigh adsorption of typical antibiotics onto novel hierarchical porous carbons derived from renewable lignin via halloysite nanotubes-template and in-situ activation. Chem. Eng. J. 2016, 304, 609-620. [CrossRef]

45. Das, S.; Jana, S. A tubular nanoreactor directing the formation of in situ iron oxide nanorods with superior photocatalytic activity. Environ. Sci. Nano 2017, 4, 596-603. [CrossRef]

46. Zhang, J.; Yan, Z.; Ouyang, J.; Yang, H.; Chen, D. Highly dispersed sepiolite-based organic modified nanofibers for enhanced adsorption of congo red. Appl. Clay Sci. 2018, 157, 76-85. [CrossRef]

47. Deng, L.; Yuan, P.; Liu, D.; Annabi-Bergaya, F.; Zhou, J.; Chen, F.; Liu, Z. Effects of microstructure of clay minerals, montmorillonite, kaolinite and halloysite, on their benzene adsorption behaviors. Appl. Clay Sci. 2017, 143, 184-191. [CrossRef]

48. Makaremi, M.; Pasbakhsh, P.; Cavallaro, G.; Lazzara, G.; Aw, Y.K.; Lee, S.M.; Milioto, S. Effect of morphology and size of halloysite nanotubes on functional pectin bionanocomposites for food packaging applications. ACS Appl. Mater Inter. 2017, 9, 17476-17488. [CrossRef] [PubMed]

49. Lisuzzo, L.; Cavallaro, G.; Parisi, F.; Milioto, S.; Lazzara, G. Colloidal Stability of Halloysite Clay Nanotubes. Ceram. Int. 2018, in press. [CrossRef]

50. Bertolino, V.; Cavallaro, G.; Lazzara, G.; Milioto, S.; Parisi, F. Biopolymer-targeted adsorption onto halloysite nanotubes in aqueous media. Langmuir 2017, 33, 3317-3323. [CrossRef] [PubMed]

51. Cavallaro, G.; Lazzara, G.; Milioto, S.; Parisi, F. Hydrophobically modified halloysite nanotubes as reverse micelles for water-in-oil emulsion. Langmuir 2015, 31, 7472-7478. [CrossRef] [PubMed]

52. Scott, G.; Wiles, D.M. Programmed-life plastics from polyolefins: A new look at sustainability. Biomacromolecules 2001, 2, 615-622. [CrossRef] [PubMed] 